\title{
Research on Cutting Force and Surface Integrity of TC18 Titanium Alloy by Longitudinal Ultrasonic Vibration Assisted Milling
}

\section{Weibo Xie}

Chongqing University https://orcid.org/0000-0003-3564-1361

\section{Xikui Wang ( 26106@pdsu.edu.cn)}

Henan Engineering Research Center for Ultrasonic Technology and Application, Pingdingshan University, Pingdingshan, 467000, China

\section{Erbo Liu}

Henan Engineering Research Center for Ultrasonic Technology and Application, Pingdingshan University, Pingdingshan, 467000, China

\section{Jian Wang}

State Key Laboratory of Mechanical Transmissions, Chongqing University, Chongqing 400044, China.

\section{Xiaobin Tang}

State Key Laboratory of Mechanical Transmissions, Chongqing University, Chongqing 400044, China.

\section{Guangxi Li}

Henan Engineering Research Center for Ultrasonic Technology and Application, Pingdingshan University, Pingdingshan, 467000, China

\section{Jian Zhang}

State Key Laboratory of Mechanical Transmissions, Chongqing University, Chongqing 400044, China.

\section{Liquan Yang}

Henan Engineering Research Center for Ultrasonic Technology and Application, Pingdingshan University, Pingdingshan, 467000, China

\section{Yongbo Chai}

Henan Engineering Research Center for Ultrasonic Technology and Application, Pingdingshan University, Pingdingshan, 467000, China

\section{Bo Zhao}

Henan Engineering Research Center for Ultrasonic Technology and Application, Pingdingshan University, Pingdingshan, 467000, China

\section{Research Article}

Keywords: Longitudinal ultrasonic vibration assisted milling, TC18 titanium alloy, Cutting Force, Surface Integrity 
Posted Date: June 25th, 2021

DOl: https://doi.org/10.21203/rs.3.rs-630708/v1

License: (c) (i) This work is licensed under a Creative Commons Attribution 4.0 International License. Read Full License

Version of Record: A version of this preprint was published at The International Journal of Advanced Manufacturing Technology on January 13th, 2022. See the published version at https://doi.org/10.1007/s00170-021-08532-y. 


\section{Abstract}

In order to study the influence of rotational speed and amplitude on the surface integrity, TC18 titanium alloy samples were milled by the process of conventional milling and longitudinal ultrasonic vibration assisted milling. The experimental data were obtained by dynamometer, thermometer, scanning electron microscope, X-ray diffractometer and three-dimensional surface topography instrument for observation and analysis. The results show that the rotational speed has a significant effect on the cutting force, cutting temperature, surface morphology and surface residual stress. Compared with ordinary milling, the surface micro-texture produced by ultrasonic vibration milling is more regular, , and with the increase of rotational speed, the influence of ultrasonic vibration on cutting force and cutting temperature decrease. There are adverse effects on surface roughness after ultrasonic vibration superposition. The influence of ultrasonic vibration on the surface residual compressive stress is also greatly reduced when the rotational speed is greater than $2400 \mathrm{rpm}$. In addition, a certain depth of plastic deformation layer can be formed under the surface of ultrasonic vibration machining, and the depth of deformation layer increases with the increase of vibration.

\section{Introduction}

In the modern manufacturing industry, the use range and number of difficult-to-machine materials are increasing rapidly. There are still many difficulties and challenges in using traditional processing technologies to process difficult-to-machine materials with high quality, high efficiency and low cost $[1,2]$. TC18 is a kind of $a+\beta$ titanium alloy with excellent comprehensive performance, which is widely used in structural parts such as aircraft landing gear and other load-bearing parts in aerospace industry [3-5]. But because of its high-temperature strength, low elastic modulus, low thermal conductivity and easy chemical reaction with other substances, it is classified as difficult to process materials $[6,7]$.

Cutting force and cutting temperature is important physical parameters for the cutting process[8]. The size of the cutting force determines the power consumed during the cutting process and the deformation of the machining process system. At the same time, the cutting force also directly affects the generation of cutting heat, and further affects the durability of the tool, which also has a direct impact on the machining accuracy and machining quality. [6,9-11]. And titanium alloy produces high cutting force, high cutting temperature and serious cutting vibration in the process of machining, the production efficiency of traditional machining is greatly reduced[9]. Ultrasonic vibration machining technology is a special machining technology that applies ultra-high frequency micron-level vibration to the tool or workpiece along a certain direction based on the relative motion of the tool and the workpiece[1, 12]. Ultrasonic vibration machining technology can realize intermittent cutting. In the cutting process, it can effectively reduce the cutting force, reduce the cutting temperature, improve the stability of the machining process, increase the surface residual compressive stress, obtain more regular surface microstructure, and form excellent microstructure (nanocrystalline / fine-grained whole lamellar compact structure) on the surface layer[13-18], Widely used in machining difficult-to-machine materials[19, 20]. 
At present, the research on the cutting force and surface integrity of titanium alloy cutting is mostly concentrated on the atypical titanium alloy Ti-6Al-4V[2, 21-27]. The research on TC18 titanium alloy mainly focuses on the thermal deformation behavior, while the research on milling is rarely reported[3, 28-35]. Taking TC18 titanium alloy as the research object, CM (conventional milling ) and L-UVAM (Longitudinal ultrasonic vibration assisted milling) tests were carried out at different spindle speeds. The influence of spindle speed on cutting force, cutting temperature and machined surface quality was analyzed. On the basis of the influence of temperature and the quality of the processed surface, the influence of ultrasonic amplitude on the processed surface morphology and surface microstructure is studied, laying the foundation for the high-quality manufacturing of TC18 titanium alloy.

\section{Kinematic Analysis Of Tool-workpiece}

L-UVAM applies a longitudinal vibration parallel to the axial direction of the tool through the longitudinal horn to make the front end of the tool intermittent cutting, and the cutting-edge trajectory of longitudinal ultrasonic vibration milling can be obtained. Figure 1 schematically illustrates the processing principle of this method. The coordinate system $O-X Y Z$ is fixed on the workpiece, and the kinematics analysis of the L-UVAM cutting-edge is carried out with the $P$ point on the edge of the end mill as the reference point. Its motion is composed of the feed speed in the $Y$-direction, the ultrasonic vibration in the $Z$-direction and the rotation around the tool spindle. In order to facilitate the study, the initial feed direction of the tool is $Y$ direction, the ultrasonic vibration direction is $Z$-direction, the end mill radius is $R$, the feed speed is $v_{w}$, the amplitude of the ultrasonic vibration is $A$, the frequency is $f$, and the spindle speed is $n_{s}$. The trajectory of cutting-edge reference point $P$ can be obtained, and the trajectory equation for any point at the cuttingedge can be expressed as:

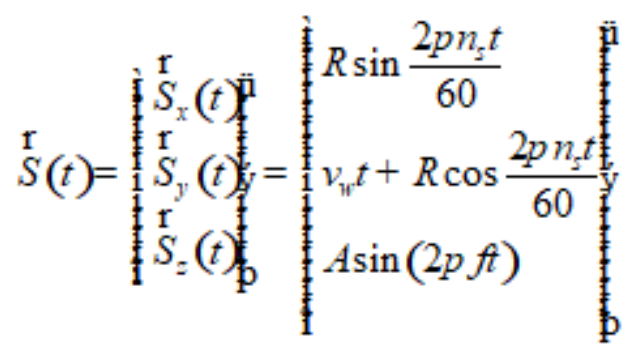

The relative motion path between the reference point of the outer edge cutting-edge and the workpiece is a spatial curve in L-UVAM, and a two-dimensional simple curve in CM (as shown in Fig. 2(a)). The cutting depth of L-UVAM cutting-edge changes periodically, and its maximum value is greater than that of CM, thus improving the material removal rate, and producing high-frequency impact, smearing and ironing effects on the machined surface. In addition, due to the motion trajectory of the cutting-edge is approximately sinusoidal, the motion trajectory of all cutting-edges interacted to form regular micro textures, thus obtaining better surface morphology, and Fig. 2(b) shows multiple trajectory curves.

\section{Experimental Design}




\subsection{Experimental device}

In this study, a CNC machining center ( Henfux-HFM 700L ) with conventional milling and ultrasonic milling functions was adopted. The machine spindle comprises of the piezoelectric actuator, concentrating horn and tool holder. It is inductively powered by a transmitting coil (fixed to the machine) and a receiving coil (rotating coaxially with the spindle). Ultrasonic vibrations are generated by the pieactuator in a coaxial direction to the main spindle. Maximum displacement is amplified by the horn before being transferred to the cutting tool[36]. Titanium alloy processing requires good thermal conductivity of tool substrate material, small roughness of coating surface and weak affinity between coating material and titanium alloy. In this experiment, four-edge integrated cemented carbide arc end milling cutter ( model: TM-4R-D8.0R1.0 ) produced by Zhuzhou Diamond Tool Co., Ltd, diameter 8 mm, blade length $20 \mathrm{~mm}$, total length $60 \mathrm{~mm}$, coated with AICrXN coating. This tool is not specially designed to improve the machinability of L-UVAM, and will not significantly affect the test results, so it is easier to identify the machining effect. Figure 3 shows the machining device of the milling sample.

Adjust the ultrasonic process parameters in advance, after ultrasonic calibration, select the appropriate parameter setting, fixed ultrasonic device power, ultrasonic vibration always follows the tool axial direction. The sample size is $15 \mathrm{~mm} \times 8 \mathrm{~mm} \times 6 \mathrm{~mm}$, in CM and L-UVAM, each sample surface needs a milling process to achieve the final sample surface. No external cutting fluid is used during the test. Turn on the dynamometer and thermometer before the start of the milling process to ensure that the cutting force and temperature signals are collected throughout the milling test. After milling, stop the force signal acquisition and temperature measurement.

\subsection{Workpiece material}

Make specimens for all tests from the same batch of materials to prevent additional effects due to chemical or metallurgical changes. The raw material alloy is the equiaxed a-structured TC18 titanium alloy bar provided by Chongqing Kingsley Aeronautical Material Technology Co., Ltd,. The matrix metallography of the raw material alloy is shown in Fig. 4. The material has good comprehensive properties of strength, plasticity and corrosion resistance, and has low elongation at break and yield strength, and its mechanical properties are shown in Table 1.

Table 1

Mechanical properties of TC18 titanium alloy at room temperature

\begin{tabular}{|llll|}
\hline Tensile strength /MPa & Yield strength /MPa & Elongation /\% & Percentage reduction of area /\% \\
\hline 1220 & 1162 & 17.4 & 48.4 \\
\hline 3.3 Experimental parameters
\end{tabular}

The purpose of this study is to quantitatively analyze the effect of L-UVAM speed on the cutting force and surface integrity of TC18 titanium alloy, on this basis, the influence of ultrasonic amplitude on machined surface morphology and surface microstructure was studied. Tests included CM and L-UVAM, and the 
feed rate of $f_{z}$ cutting depth of $a_{p}$, cutting width of $a_{e}$ and vibration frequency of $f$ remain the same, Then, revolution speed $n_{s}$ and vibration amplitude $A$ are variables, and the specific design parameters are shown in Table 2.

Table 2

Experimental parameter settings

\begin{tabular}{|lllllll|}
\hline No. & Milling parameters & & & & \multicolumn{2}{l|}{ Vibration parameters } \\
\cline { 2 - 4 } & $\begin{array}{l}\text { Revolution speed } \\
(\mathrm{rpm})\end{array}$ & $\begin{array}{l}\text { Feed per } \\
\text { Tooth (mm/z) }\end{array}$ & $\begin{array}{l}\text { Depth of } \\
\text { cut (mm) }\end{array}$ & $\begin{array}{l}\text { Cutting } \\
\text { width (mm) }\end{array}$ & $\begin{array}{l}\text { Frequency } \\
(\mathrm{kHz})\end{array}$ & $\begin{array}{l}\text { Amplitude } \\
(\boldsymbol{\mu m})\end{array}$ \\
\hline 1 & $\begin{array}{l}1600,2000,2400, \\
2800,3200\end{array}$ & 0.015 & 0.2 & 6 & 33.9 & 2 \\
\hline 2 & 1600 & 0.015 & 0.2 & 6 & 33.9 & $0,2,4$ \\
\hline
\end{tabular}

\subsection{Testing method}

Table 3

Measuring parameters of residual stress

\begin{tabular}{|ll|}
\hline Content & Parameters \\
\hline Tube voltage/kV & $25 \sim 30$ \\
\hline Tube current/mA & 25 \\
\hline Target and radiation & $\mathrm{Cu} \mathrm{Ka}$ \\
\hline Filter & $\mathrm{Ni}$ \\
\hline Aperture size & $1 \mathrm{~mm} \times 5 \mathrm{~mm}$ \\
\hline Diffraction crystal and Bragg angle & $\mathrm{Ti}-213,142^{\circ}$ \\
\hline Beta angle & $\pm 19^{\circ}$ \\
\hline Normal inclination range & $\pm 42^{\circ}$ \\
\hline X-ray elasticity modulus & $\mathrm{S}_{2} / 2=11.8879 \times 10^{-6},-\mathrm{S} 1=2.97 \times 10^{-6}$ \\
\hline
\end{tabular}

piezoelectric crystal dynamometer (Kistler 5080) was used to collect real-time data of the cutting force signals online for CM and L-UVAM, The data acquisition frequency is set to $100 \mathrm{kHz}$, and the range is set to $150 \mathrm{~N}$. The surface residual stress is obtained by X-ray diffractometer (PROTO-LXRD), and the detection parameters of residual stress are shown in Table 3. The cutting temperature is obtained by a portable infrared imager(IRI-100). The micro-morphology and surface characteristic parameters of the machined surface were obtained by a desktop scanning electron microscope(COXEM) and a threedimensional surface topography instrument(NANOVEA ST400). 
After the test, the machined surface and side section of the workpiece are embedded into the sample, and the cross section of the sample is mechanically grinded and polished. Using corrosion reagent ( $5 \% \mathrm{HNO}$ $+3 \% \mathrm{HF}+92 \% \mathrm{H} 2 \mathrm{O}$ ) etching for about $20 \mathrm{~s}$, and the microstructure perpendicular to the cross section of the machined surface along the feed direction was observed with a scanning electron microscope to characterize the effect of amplitude on the grain structure.

\section{Results And Discussion}

\subsection{Surface morphology}

Figure 5 shows the surface morphology of CM and L-UVAM observed by the SEM and 3D surface topography instrument. The image shows that the CM surface has obvious tool marks, the lateral plastic flow of the material on the machined surface is relatively serious, and the surface morphology is irregular, and with obvious plough-like scratches. With the increase of cutting speed, the feature of overlapping tool marks decreases gradually (as shown in Fig. $5(\mathrm{f}) \sim$ Fig. $5(\mathrm{j})$ ). The surface texture of L-UVAM is more regular, and there are uniform vibration machining traces on the machined surface. The feed trace is covered by the ultrasonic vibration cutting trace. At low speed, the machined surface has obvious ' rib ' texture, and the overall shape of the surface is wavy. With the increase of cutting speed, the corresponding milling surface texture is more regular, and when the spindle speed reaches $2400 \mathrm{rpm}$, the surface morphology is basically uniform, and gradually changes from 'riblike' micro-texture to 'fish scale' micro-texture(as shown in Fig. 5(f) Fig. 5(j)). This micro-texture plays a positive role in improving the surface adhesion property for coatings and the surface lubrication property.

\subsection{Effect of rotational speed on cutting force, cutting temperature, roughness and surface residual stress}

According to the kinematic characteristics of ultrasonic milling, the cutting force, cutting temperature and surface roughness of the L-UVAM sample increase with the increase of the rotation speed after the ultrasonic assist is added during the cutting process (as shown Fig. 6(a)-(c)) ), the surface residual stress increases as the speed increases in the range of 1600-2000 rpm. When the speed exceeds $2000 \mathrm{rpm}$, the surface residual stress shows a decreasing trend (as shown in Fig. 6(d)). Further analysis found that when the rotation speed is $2400 \mathrm{rpm}$, the residual stress on the surface of the L-UVAM sample increases most significantly compared to the $\mathrm{CM}$ sample, and the increase percentage can reach $50.9 \%$. The main reason is that the lower cutting force and cutting temperature of the L-UVAM surface reduce the plastic bulging effect and thermal effect in the formation of residual stress, and at the same time, the L-UVAM sample is caused by the impact ironing of the longitudinal high-frequency ultrasonic vibration, the value of the residual compressive stress on the surface is greater than that of the CM sample. Further, while the ultrasonic assists in reducing the cutting force, it effectively increases the diffusion time and diffusion space of the cutting temperature, and also increases the air flow between the tool and the workpiece, and promotes the temperature diffusion on the surface, resulting in the reduction of the surface temperature 
for the L-UVAM sample. Thus, the cutting temperature of this sample is significantly lower than that of the $\mathrm{CM}$ sample, and the reduction percentage of the cutting temperature can reach $19.5 \%$.

For the $\mathrm{CM}$ sample, as the speed increases, the surface cutting force and cutting temperature generally show a trend of first decreasing and then increasing (as shown in Fig. 6(a)-(b)), and the surface roughness does not appear significant changes (as shown in Fig. 6(c)), while the surface residual stress gradually decreases (as shown in Fig. 6(d)). Further analysis found that at the same rotation speed, the cutting force and cutting temperature generated by processing the L-UVAM sample after adding ultrasound were significantly lower than that of the $\mathrm{CM}$ sample, and the surface roughness and surface residual stress of the L-UVAM sample were lower than that of the CM sample. It shows that the ultrasonic cutting process is beneficial to protect the tool and obtain greater surface roughness and residual stress. In-depth analysis found that under the condition of low speed (1600 rpm), the cutting force and cutting temperature of the processed L-UVAM samples were reduced most significantly, and the cutting force reduction percentage was up to $34.1 \%$. This is because after ultrasonic vibration is applied, the cutting force signal changes from a simple curve to a dense pulse beam, which causes the cutting force signal of the L-UVAM sample to change from a continuous signal to a pulsed force signal, showing obvious oscillation characteristics (as shown in Fig. 7). The changing cutting depth and the pulling action of the tool on the cutting debris cause oscillating friction between the debris and the tool. This frictional resistance is transformed into a force that is beneficial to the cutting process, thereby effectively reducing the surface cutting force; but as the speed increases, the reduction effect of ultrasonic-assisted cutting force will be significantly reduced (as shown in Fig. 6(a)) [37, 38].

\subsection{Effect of amplitude on surface morphology and microstructure}

To study the effect of ultrasonic vibration on the surface topography, the SEM images of different samples with different processing parameters are observed (as shown in Fig. 8(a) Fig. 8 (c)). With the increase of ultrasonic amplitude, the tool ironing traces left on the surface of the work piece increase as expected, and the ultrasonic vibration causes more obvious cutting marks on the machined surface. In order to further study the effect of ultrasonic vibration on the grain structure, we observed the crosssectional structure of the sample (as shown in Fig. 8 (d) to Fig. 8 (f)). It can be seen that the thermalmechanical coupling in the cutting process leads to the distortion of the grain boundary of the surface material of the work piece, and the grains are elongated and refined along the cutting direction, and however, no subsurface defects such as cracks or tearing were observed. A plastic deformation layer with a certain depth is formed under the machined surface. The depth of the deformation layer increases with the increase of the amplitude, and the degree of grain deformation becomes more obvious with the increase of the amplitude. When the amplitude is $4 \mu \mathrm{m}$, the depth of the deformation layer can reach about $5.2 \mu \mathrm{m}$.

\section{Conclusion}


(1) In general, ultrasonic-assisted milling is beneficial to reduce cutting force and cutting temperature, and increase surface residual compressive stress. Compared with the $\mathrm{CM}$ sample, the average cutting force on the surface of the L-UVAM sample can be reduced by $34.1 \%$, the cutting temperature can be reduced by $19.5 \%$, and the surface residual compressive stress can be increased by $50.9 \%$; as the speed increases, both the cut force and the cutting temperature will increase. When the speed is greater than $2000 \mathrm{rpm}$, the surface residual compressive stress will decrease as the speed increases.

(2) Ultrasonic vibration has an important influence on the surface morphology and grain structure. Compared with the CM sample, the surface of the L-UVAM sample can obtain a more regular microscopic morphology and greater roughness. With the increase of the rotation speed, the surface roughness increases; the grain boundary under the surface of the L-UVAM sample is distorted, the crystal grains are elongated and refined along the cutting direction to form a processing deformation layer with a certain depth, and the depth of the deformation layer increases with the increase of the amplitude; when the amplitude is $4 \mu \mathrm{m}$, the depth of the deformed layer can reach about $5.2 \mu \mathrm{m}$.

(3) This research systematically studied the influence of ultrasonic-assisted milling process on material surface cutting force, cutting temperature, surface morphology and grain structure, and had laid a certain theoretical foundation for further research and optimization of surface ultrasonic milling process.

\section{Declarations}

Author contribution

Conceptualization was handled by Weibo Xie and Guangxi Li; visualization was handled by Weibo Xie; writing of the original draft was handled by Weibo Xie and Xikui Wang; supervision was handled by Jian Wang and Bo Zhao; data curation was handled by Weibo Xie and Yongbo Hou; review and editing was handled by Xiaobin Tang and Jian Zhang; funding acquisition was handled by Jian Wang, Guangxi Li and Liquan Yang.

Funding

This Research Fund for High-level Talents of Pingdingshan University (PXY-BSQD-202014), National Project Cultivation Fund of Pingdingshan University (PXY-PYJJ-202105), Key Research Project of Institutions of Higher Education in Henan Province (21A430029) and Henan science and technology tackling key project (212102210349).

Declarations

Ethics approval The authors state that the present work is in compliance with the ethical standards.

Conflict of interests The authors declare no competing interests.

\section{References}


[1] Chenbing N, Lida Z, Jinsheng N. (2019) Research on the Characteristics of Cutting Force Signal and Chip in Ultrasonic Vibration-assisted Milling of Titanium Alloys. Journal of Mechanical Engineering,55:207-216. doi: 10.3901/JME.2019.07.207

[2] Renke K, Fujian M, Zhigang D. (2012) Ultrasonic assisted machining of difficult-to-cut material. Aeronautical Manufacturing Technology,412:44-49. doi: 10.16080/j.issn1671-833x.2012.16.022

[3] Changming Z, Yongxin W. (2019) Cutting Force and Surface Roughness of Turning on TC18 Titanium Alloy. Materials for Mechanical Engineering,43:69-73. doi: 10.11973/jxgccl201907015

[4] Shao H, Shan D, Wang K, Zhang G, Zhao Y. (2019) Massive a precipitation selectivity and tensile fracture behavior of TC18 alloy. Journal of Alloys and Compounds,797:10-17. doi:

10.1016/j.jallcom.2019.04.315

[5] Ma J, Luo D, Liao X, Zhang Z, Huang Y, Lu J. (2021) Tool wear mechanism and prediction in milling TC18 titanium alloy using deep learning. Measurement,173:108554. doi:

10.1016/j.measurement.2020.108554

[6] Bandapalli C, Singh KK, Sutaria BM, Bhatt DV. (2018) Experimental investigation of top burr formation in high-speed micro-end milling of titanium alloy. Machining science and technology,22:9891011. doi: $10.1080 / 10910344.2018 .1449213$

[7] Zhang C, Mu A, Wang Y, Zhang H. (2020) Study on Dynamic Mechanical Properties and Constitutive Model Construction of TC18 Titanium Alloy. Metals,10:44. doi: 10.3390/met10010044

[8] Kiran K, Kayacan MC. (2019) Cutting force modeling and accurate measurement in milling of flexible workpieces. Mechanical Systems and Signal Processing,133:106284. doi: 10.1016/j.ymssp.2019.106284

[9] Verma GC, Pandey PM, Dixit US. (2018) Modeling of static machining force in axial ultrasonicvibration assisted milling considering acoustic softening. International Journal of Mechanical Sciences,136:1-16. doi: 10.1016/j.ijmecsci.2017.11.048

[10] Han X, Zhang D. (2020) Effects of separating characteristics in ultrasonic elliptical vibration-assisted milling on cutting force, chip, and surface morphologies. The International Journal of Advanced Manufacturing Technology,108:3075-3084. doi: 10.1007/s00170-020-05463-y

[11] Liu J, Sun J, Zaman UKU, Chen W. (2020) Influence of Wear and Tool Geometry on the Chatter, Cutting Force, and Surface Integrity of TB6 Titanium Alloy with Solid Carbide Cutters of Different Geometry. Strojniški vestnik - Journal of Mechanical Engineering,66:709-723. doi: 10.5545/svjme.2020.6714

[12] Yundian Z.(1995) Ultrasonic machining and its application. National Defense Industry Press, Beijing 
[13] Jiajia L, Xinggang J, Ze G, Mingliang Z, Deyuan Z. (2019) Investigation of the Effect of Vibration Amplitude on the Surface Integrity in High-speed Rotary Ultrasonic Elliptical Machining for Side Milling of Ti-6Al-4V. Journal of Mechanical Engineering,55:215-223. doi®10.3901/JME.2019.11.215

[14] Jamshidi H, Nategh MJ. (2013) Theoretical and experimental investigation of the frictional behavior of the tool-chip interface in ultrasonic-vibration assisted turning. International Journal of Machine Tools and Manufacture,65:1-7. doi: 10.1016/j.ijmachtools.2012.09.004

[15] Chern G, Chang Y. (2006) Using two-dimensional vibration cutting for micro-milling. International Journal of Machine Tools and Manufacture,46:659-666. doi: 10.1016/j.ijmachtools.2005.07.006

[16] Zhang Y, Zhao B, Wang Y, Chen F. (2017) Effect of machining parameters on the stability of separated and unseparated ultrasonic vibration of feed direction assisted milling. Journal of Mechanical Science and Technology,31:851-858. doi: 10.1007/s12206-017-0137-x

[17] Xinggang J, Haitong L, Huimin L, Jiandui D, Deyuan Z, Ahmed M. (2014) Investigation of Ultrasonic Elliptical Vibration Milling of Thin-walled Titanium Alloy Parts. Acta Armamentarii,35:1891-1897. doi: 10.3969 /j. issn. 1000-1093. 2014. 11. 022

[18] Xiao M, Sato K, Karube S, Soutome T. (2003) The effect of tool nose radius in ultrasonic vibration cutting of hard metal. International Journal of Machine Tools and Manufacture,43:1375-1382. doi: 10.1016/S0890-6955(03)00129-9

[19] Babitsky VI, Kalashnikov AN, Meadows A, Wijesundara AAHP. (2003) Ultrasonically assisted turning of aviation materials. Journal of Materials Processing Technology,132:157-167. doi:

https://doi.org/10.1016/S0924-0136(02)00844-0

[20] Ali MH, Khidhir BA, Ansari MNM, Mohamed B. (2019) FEM to predict the effect of feed rate on surface roughness with cutting force during face milling of titanium alloy. HBRC Journal,9:263-269. doi: 10.1016/j.hbrcj.2013.05.003

[21] Sahoo P, Pratap T, Patra K. (2019) A hybrid modelling approach towards prediction of cutting forces in micro end milling of Ti-6Al-4V titanium alloy. International Journal of Mechanical Sciences, 150:495509. doi: 10.1016/j.ijmecsci.2018.10.032

[22] Ni C, Zhu L, Liu C, Yang Z. (2018) Analytical modeling of tool-workpiece contact rate and experimental study in ultrasonic vibration-assisted milling of Ti-6Al-4V. International Journal of Mechanical Sciences,142-143:97-111. doi: 10.1016/j.jjmecsci.2018.04.037

[23] Zhang X, Luo M, Zhang D. (2018) High Performance Cutting of Titanium Alloy Based on the Thermomechanical coupling effect. Procedia CIRP,77:126-129. doi: 10.1016/j.procir.2018.08.247

[24] Daramola O0, Tlhabadira I, Olajide JL, Daniyan IA, Sadiku ER, Masu L, VanStaden LR. (2019) Process Design for Optimal Minimization of Resultant Cutting Force during the Machining of Ti-6Al-4V: 
Response Surface Method and Desirability Function Analysis. Procedia CIRP,84:854-860. doi: 10.1016/j.procir.2019.04.185

[25] Kechagias JD, Aslani K, Fountas NA, Vaxevanidis NM, Manolakos DE. (2020) A comparative investigation of Taguchi and full factorial design for machinability prediction in turning of a titanium alloy. Measurement,151:107213. doi: 10.1016/j.measurement.2019.107213

[26] Chen G, Ren C, Zou Y, Qin X, Lu L, Li S. (2019) Mechanism for material removal in ultrasonic vibration helical milling of Ti 6Al $4 \mathrm{~V}$ alloy. International Journal of Machine Tools and Manufacture,138:1-13. doi: 10.1016/j.jimachtools.2018.11.001

[27] P. A. Rey JLJS. (2016) Modelling of cutting forces in orbital drilling of titanium alloy Ti-6Al-4V. International Journal of Machine Tools and Manufacture,106:75-88. doi:

10.1016/j.jjmachtools.2016.04.006

[28] Ning YQ, Xie BC, Liang HQ, Li H, Yang XM, Guo HZ. (2015) Dynamic softening behavior of TC18 titanium alloy during hot deformation. Materials \& Design,71:68-77. doi: 10.1016/j.matdes.2015.01.009

[29] Shuyu S, Weijie L. (2016) Microstructure and Mechanical Properties of TC18 Titanium Alloy. Rare Metal Materials and Engineering,45:1138-1141. doi: https://doi.org/10.1016/S1875-5372(16)30108-4

[30] Ning YQ, Luo X, Liang HQ, Guo HZ, Zhang JL, Tan K. (2015) Competition between dynamic recovery and recrystallization during hot deformation for TC18 titanium alloy. Materials Science and Engineering: A,635:77-85. doi: 10.1016/j.msea.2015.03.071

[31] Qu FS, Zhou YH, Zhang LY, Wang ZH, Zhou J. (2015) Research on hot deformation behavior of Ti5Al-5Mo-5V-1Cr-1Fe alloy. Materials \& Design,69:153-162. doi: 10.1016/j.matdes.2014.12.021

[32] Ran C, Chen P, Li L, Zhang W. (2017) Dynamic shear deformation and failure of Ti-5Al-5Mo-5V-1Cr1Fe titanium alloy. Materials Science and Engineering: A,694:41-47. doi: 10.1016/j.msea.2017.03.114

[33] Hu Z, Yi D, Liu H, Zhou X, Zhou H. (2019) New type of macrozone in a near- $\beta$ titanium alloy Ti-5Al5Mo-5V-1Cr-1Fe. Materials Letters,238:6-9. doi: 10.1016/j.matlet.2018.11.135

[34] Liang H, Guo H, Ning Y, Peng X, Qin C, Shi Z, Nan Y. (2014) Dynamic recrystallization behavior of Ti5Al-5Mo-5V-1Cr-1Fe alloy. Materials \& Design,63:798-804. doi: 10.1016/j.matdes.2014.06.064

[35] Ahmed M, Savvakin DG, Ivasishin OM, Pereloma EV. (2014) The effect of ageing on microstructure and mechanical properties of powder Ti-5Al-5Mo-5V-1Cr-1Fe alloy. Materials Science and Engineering: A,605:89-97. doi: 10.1016/j.msea.2014.03.030

[36] Suárez A, Veiga F, de Lacalle LNL, Polvorosa R, Lutze S, Wretland A. (2016) Effects of UltrasonicsAssisted Face Milling on Surface Integrity and Fatigue Life of Ni-Alloy 718. Journal of Materials Engineering and Performance,25:5076-5086. doi: 10.1007/s11665-016-2343-6 
[37] Xun L, Deyuan Z. (2010) Experimental Study on the Unseparated Ultrasonic Elliptical Vibration Cutting. JOURNAL OF MECHANICAL ENGINEERING,46:177-182. doi: 10.3901/JME.2010.19.177

[38] Wen L, Jiao Y, Leiping L. (2013) Study on the unseparated ultrasonic elliptical vibration cutting force. Acta Aeronautica ET Astronautica Sinica,34:2241-2248. doi: 10.7527/S1000-6893.2013.0294

\section{Figures}

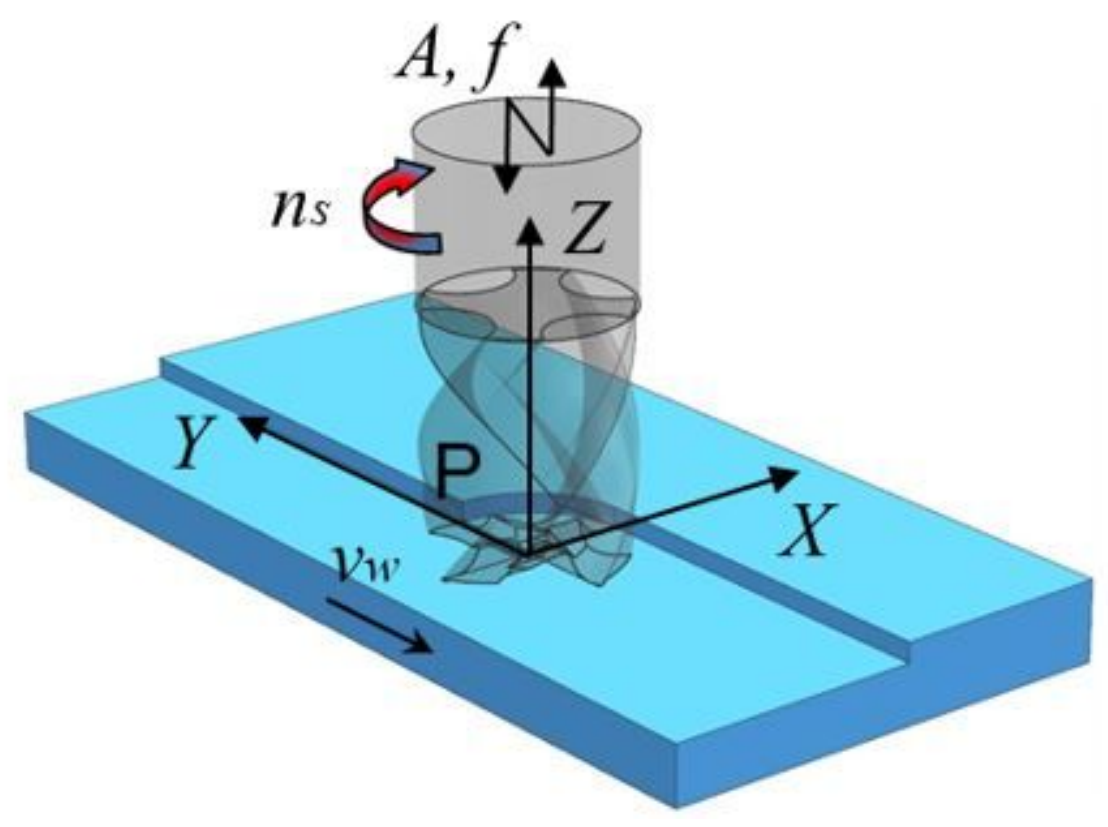

Figure 1

L-UVAM principle

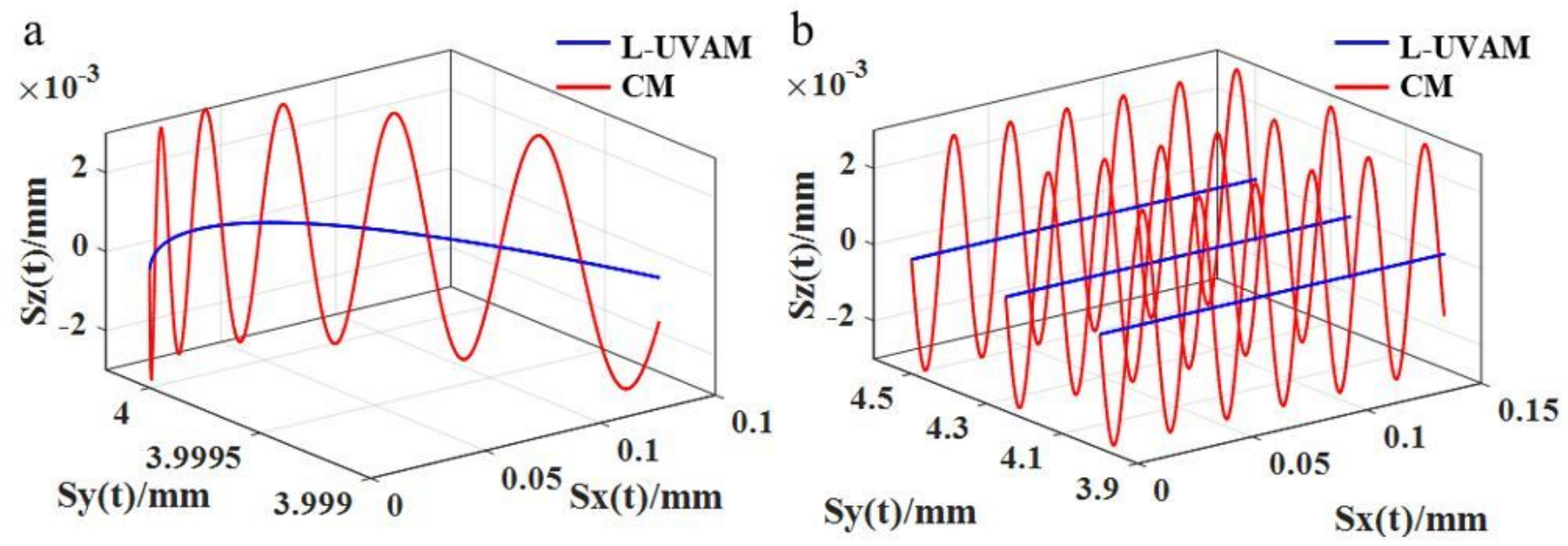

Figure 2 


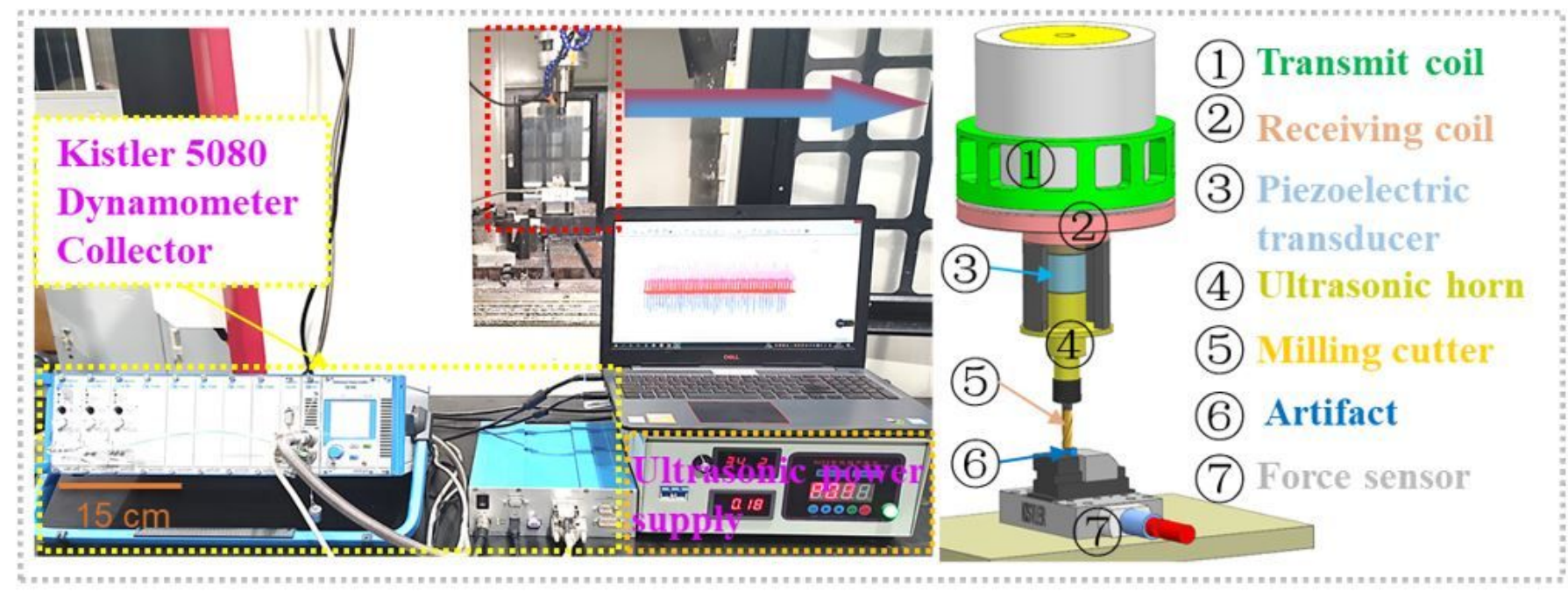

Figure 3

Processing device

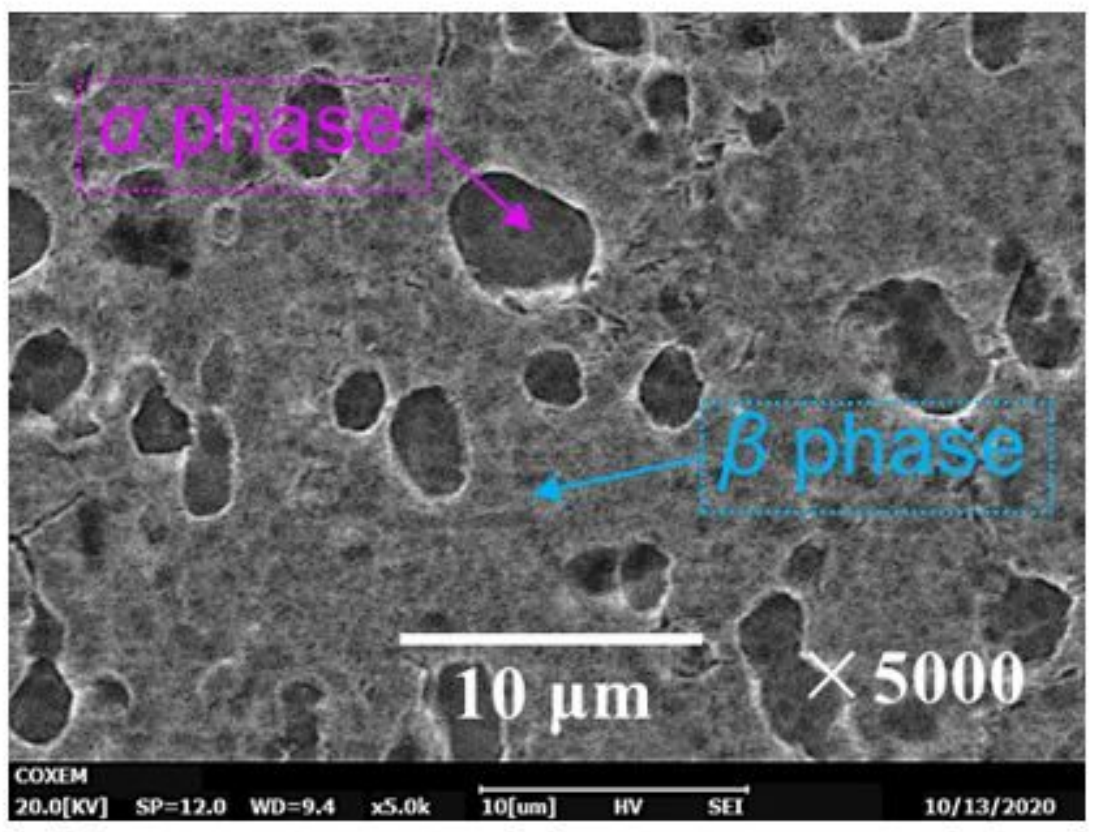

Figure 4

SEM photos of metallographic organization of TC18 titanium alloy matrix $\times 5000$ 

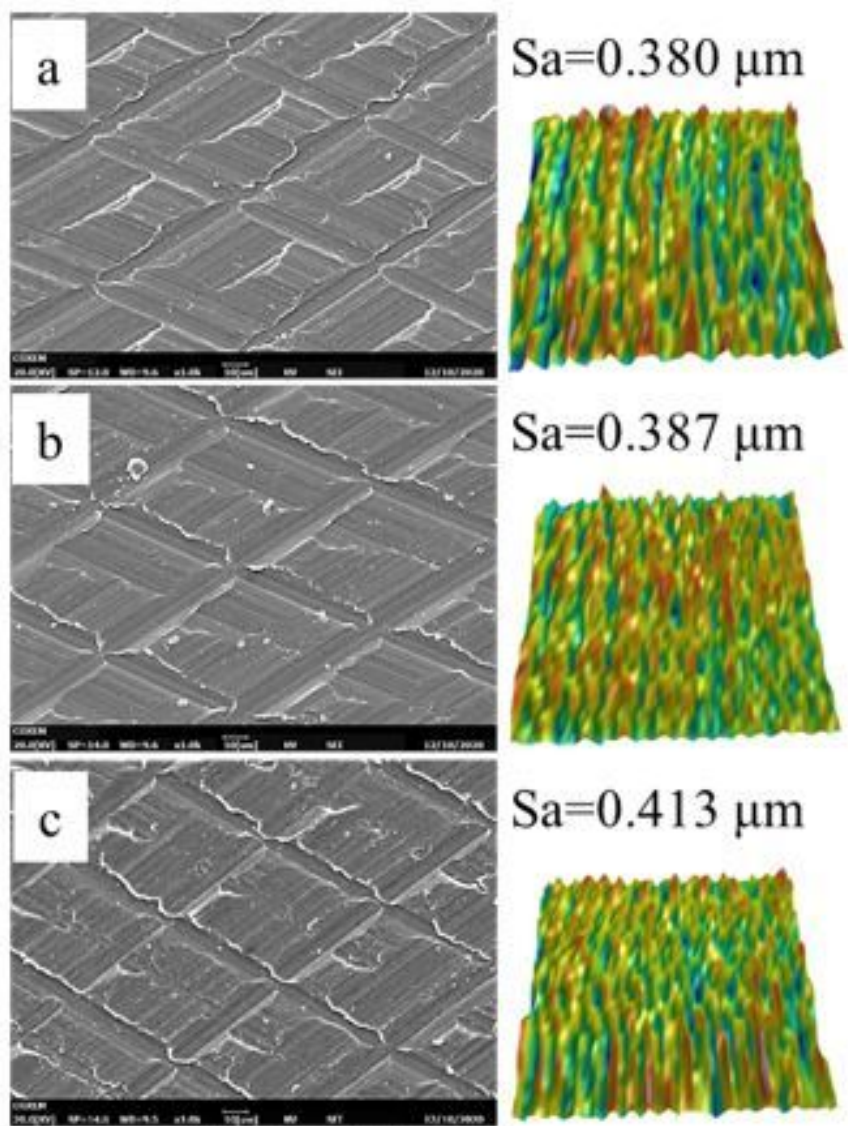

$\mathrm{Sa}=0.413 \mu \mathrm{m}$
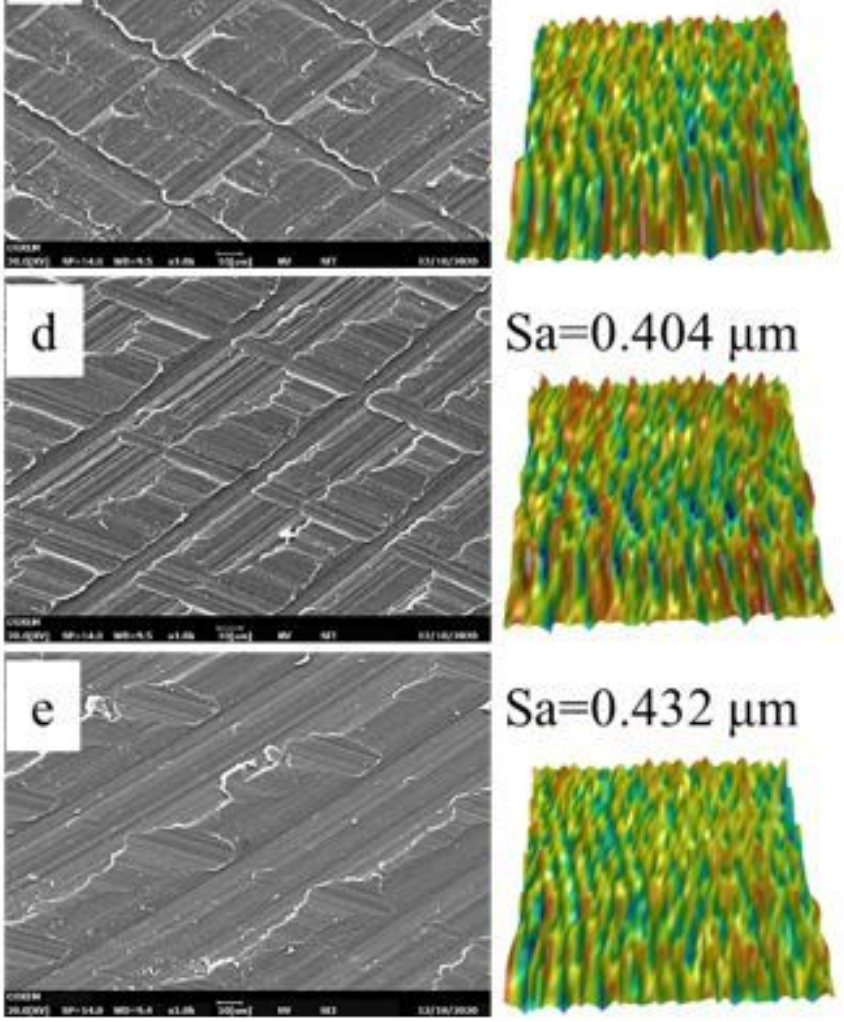
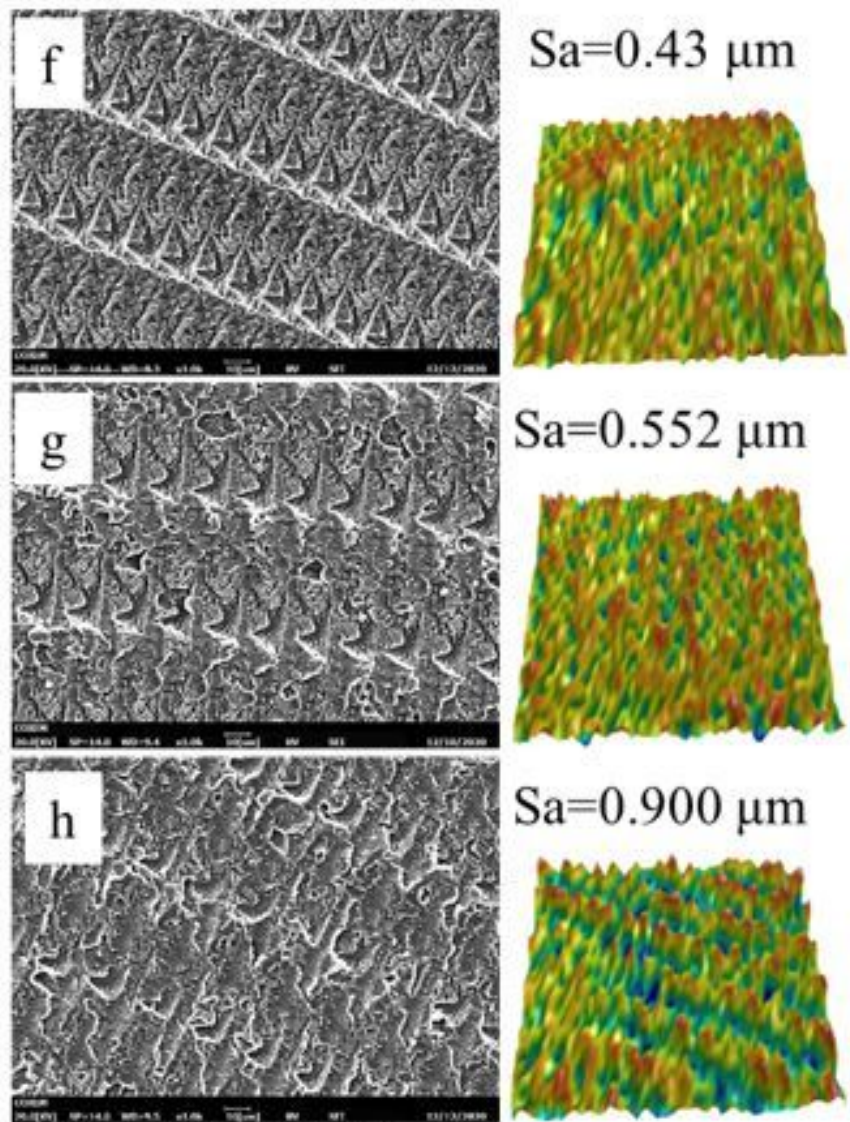

$\mathrm{Sa}=0.900 \mu \mathrm{m}$
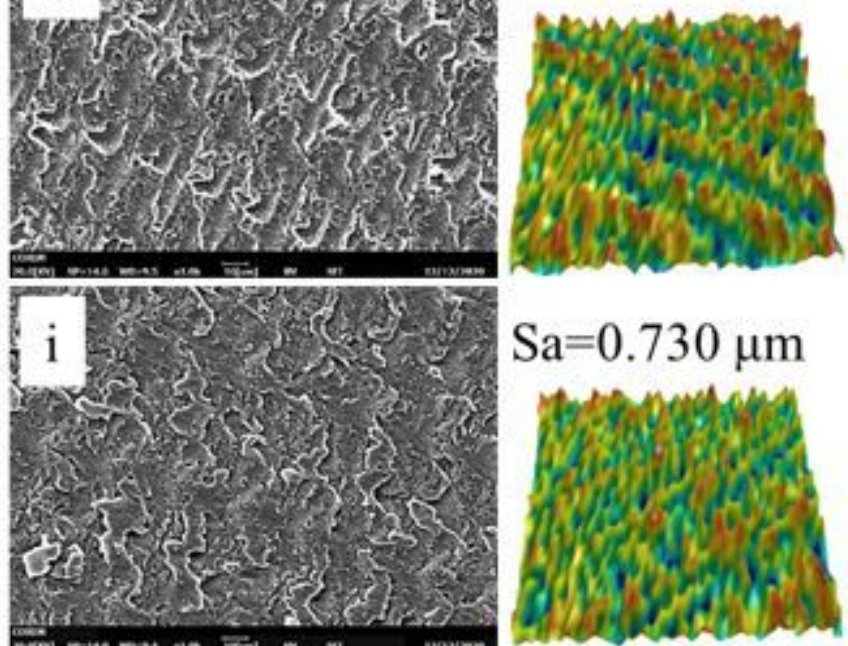

$\mathrm{Sa}=0.730 \mu \mathrm{m}$
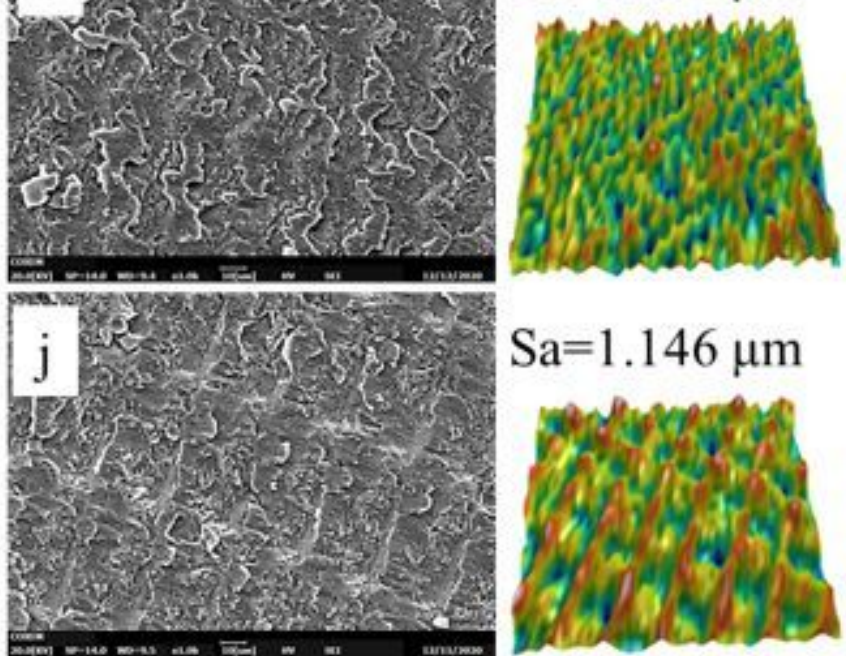

Figure 5

Effect of cutting speed on surface morphology of CM and L-UVAM (a) (e) Surface morphology of CM at $1600 \mathrm{rpm}, 2000 \mathrm{rpm}, 2400 \mathrm{rpm}, 2800 \mathrm{rpm}, 3200 \mathrm{rpm}$ and $3600 \mathrm{rpm} \otimes(\mathrm{f}) \sim(\mathrm{j})$ Surface morphology of LUVAM at 1600 rpm, 2000 rpm, 2400 rpm, 2800 rpm, 3200 rpm and 3600 rpm 


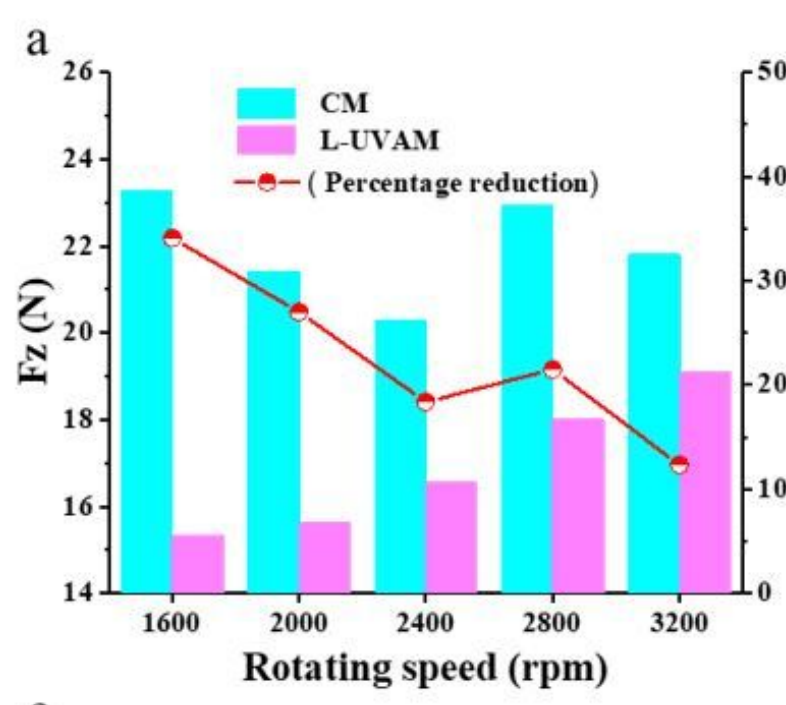

$\mathrm{b}$
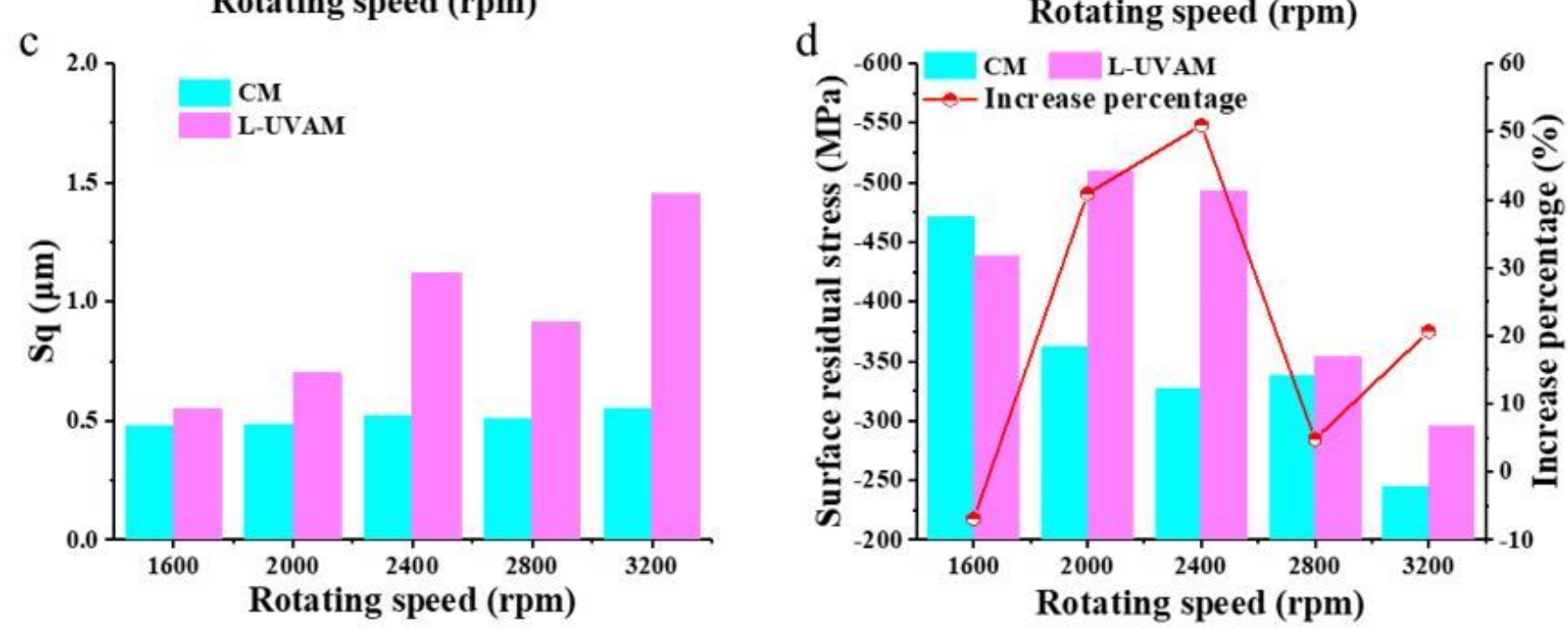

Figure 6

CM process and L-UVAM process under different rotational speeds: (a) axial component force and axial component force decrease percentage; (b) cutting temperature and cutting temperature decrease percentage; (c) surface profile height root mean square deviation Sq; (d) surface residual stress and residual stress increase percentage 

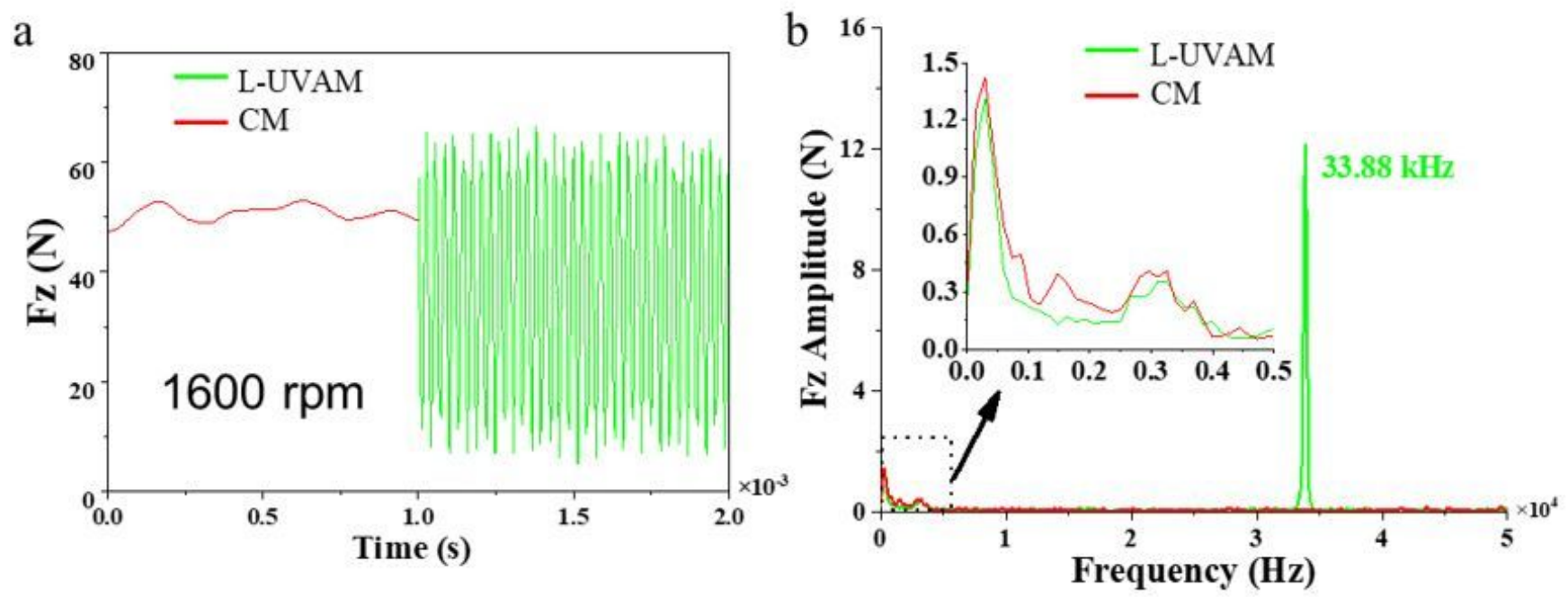

Figure 7

CM and L-UVAM (a) cutting force characteristics; (b) cutting force spectrum characteristics 

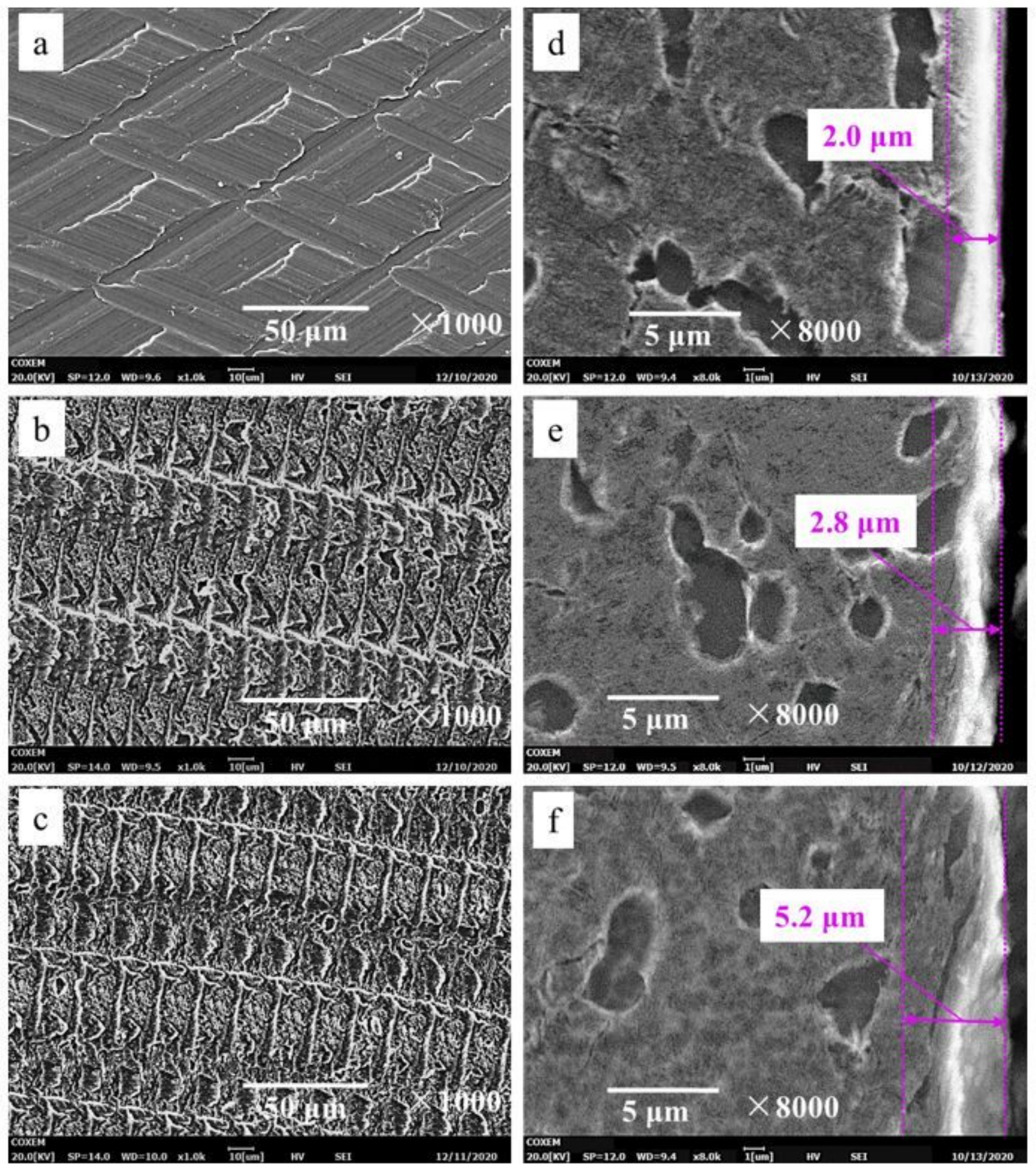

\section{Figure 8}

Surface topography of different amplitude milling (a) $C M$, (b) $A=2 \mu m$, (c) $A=4 \mu m$; Microstructure of deformation layer with different amplitude (d) $C M$, (e) $A=2 \mu m$, (f) $A=4 \mu m$

\section{Supplementary Files}


This is a list of supplementary files associated with this preprint. Click to download.

- Shareddata.rar 